\title{
Um Estudo sobre a Representação Parental de Casais Homoafetivos Masculinos
}

\author{
Brunella Carla Rodriguez ${ }^{1}$ \\ Laura Fernandes Merli \\ Programa de Pós-Graduação em Psicologia Clínica da Universidade de São Paulo, \\ São Paulo, SP, Brasil \\ Isabel Cristina Gomes \\ Instituto de Psicologia da Universidade de São Paulo, São Paulo, SP, Brasil
}

\section{Resumo}

Da família tradicional-patriarcal à família contemporânea, mudanças relevantes ocorreram, gerando uma pluralidade de modelos. O papel fundamental da família na constituição psíquica do indivíduo, frente ao crescente aparecimento de novos arranjos familiares, torna essencial construir conhecimento acerca das novas formas de se relacionar e vivenciar a parentalidade. Este trabalho objetiva apresentar os resultados de uma pesquisa que investigou as representações parentais de casais homossexuais masculinos, por meio das imagos parentais e legados geracionais. Com objetivo de compreender como se dão tais representações, bem como, suas possíveis ligações e/ou influências na relação do casal homoafetivo e, possivelmente, na família homoparental, foram entrevistados cinco casais homossexuais masculinos sem filhos e aplicado o Desenhos de Família com Estórias (DF-E) adaptado. O método utilizado foi o clínico-qualitativo e a análise feita com base no referencial psicanalítico vincular. Os resultados apontaram casais ainda muito ligados à suas famílias de origem; com questões conflitivas associadas ao processo de construção de suas identidades homossexuais; presos ao modelo de conjugalidade heteronormativa; cujos relacionamentos caracterizaram-se pela brevidade com que se tornaram compromissados, com a finalidade principal de apoio mútuo à assunção da identidade homossexual. Concluiu-se que o despreparo para deixar o lugar de filho é fator influente para não se pensar acerca da parentalidade; e está relacionado aos conflitos de cerne familiar, especialmente à falta de aceitação. Enfatizamos a necessidade de maior número de pesquisas na área, visando uma abordagem científica que propicie o estabelecimento de uma ética pautada no vínculo filiativo.

Palavras-chave: Parentalidade, representação parental, homoparentalidade, família.

\section{A Study on the Parental Representation of Homoaffective Male Couples}

\begin{abstract}
From the traditional patriarchal family, relevant changes have occurred, generating a plurality of models. The fundamental role of family in psychic constitution, ahead of the growing emergence of new family arrangements, it is considered essential the study of the new functions and forms of relating in these groups. Aiming to comprehend how these representations and its possible relations and/or influences in the homoaffective couple relation and, possibly, in the homoparental family, five homosexual couples
\end{abstract}

Endereço para correspondência: Rua Daniel Peçanha de Moraes, 255, Vila Santista, Atibaia, SP, Brasil 12941050. E-mail: brunellacarla@gmail.com, lomerli@yahoo.com.br e isagomes@usp.br 
without children have been interviewed in their own houses. The method was the clinical-qualitative and the analyses were made based on the psychoanalytical referential. The results point couples still very linked to their families of origin; with conflictive issues associated to the process of construction of their homosexual identities; stuck to the model of heterosexual couples, whose relationships are characterized for the brevity of engagement, with the main goal to be the mutual support to the homosexual identity assumption of each of them. This way, we conclude that the unpreparedness to leave the place of "son" is an influent factor to not think about parenthood; and both are related to conflicts centered in the family, specially the lack of acceptance of homosexuality. Emphasizing the need of a greater number of researches in the area of homoparenthood, aiming a scientific approach of it, and providing the establishment of an ethic punctuated in the bond.

Keywords: Parenthood, parental representation, homoparenthood, family.

\section{Un Estudio sobre la Representacion Parental de Parejas Homoafetivas Masculinas}

\section{Resumen}

Desde la familia tradicional-patriarcal hasta la familia contemporanea, mudanzas relevantes ocurrieron, generando una pluralidade de modelos. El papel fundamental de la familia en la constituicion psíquica del individuo, frente al creciente aparecimiento de nuevos arreglos familiares, se considera fundamental el estudio de las nuevas funciones y formas de se relacionar en esos grupos. Con objetivo de comprender como ocurren esas representaciones y sus posibles relaciones y/o influencias en la relación de la pareja homoafectiva y, posiblemente, en la familia homoparental, fueron entrevistados cinco parejas homosexuales masculinas sin hijos, y aplicado el Dibujos de Familia con Historias (DF-E) adaptado. El metodo fue el clinico-cualitativo y los analisis hechos com base em el referencial psicoanalitico vincular. Los resultados apuntan a parejas todavía muy ligados a sus familias de origen; con cuestiones conflictivas asociadas al proceso de construcción de sus identidades homosexuales; atados al modelo de conjugabilidad heteronormativa; cuyos relacionamientos se caracterizan por la brevedad con que se tornaron comprometidos, con la finalidad principal de apoyo mutuo a la aceptación de la identidad homosexual. Se concluye que el despreparo para dejar su sitio de "hijo" es factor influyente para no se pensar en la parentalidad; que está relacionado con conflictos de cerne familiar, especialmente la falta de aceptación de la homosexualidad. Enfatizamos la necesidad de un mayor numero de investigaciones en el área de la homoparentalidad, apuntando un abordage cientifico de este y así propiciar el establecimiento de una ética puntuada en el vinculo filiativo.

Palabras clave: Parentalidade, representacion parental, homoparentalidade, familia.

\section{A Familia e suas Transformações}

Ao longo dos anos a instituição família tem passado por mudanças de grande importância, que assinalam a passagem do modelo de família tradicional-patriarcal à família contemporânea. Autores como Borges e Coutinho (2008) e Roudinesco (2003) consideraram a flexibilidade dinâmica e estrutural dos últimos anos como uma reviravolta, um momento de crise da instituição familiar, que sofre com a perda do sentido da tradição e a maior liberdade de valores. Entretanto esse momento pode ser visto como uma etapa de construção, que obriga a família a criar novos sentidos e significações a serem atribuídos às relações familiares e aos papéis e funções exercidos pelos indivíduos que a compõem (Giddens, 1993).

Entre as transformações sofridas pela instituição familiar observa-se que o modelo tradicional da família, de configuração heterossexual, monogâmica e nuclear, passou a ser visto como invariável, inequívoco e natural, perdendo as- 
sim, sua dimensão histórica e socioconstruída (Moscheta \& Santos, 2009). As famílias vêm se constituindo de forma mais ampla e as funções de gênero se modificando. Na organização contemporânea os lugares masculinos e femininos na família não coincidem com os ocupados pelos homens e pelas mulheres; eles circulam e com mais intensidade (Amazonas \& Braga, 2006), caracterizando um acelerado processo de modernização que interfere e produz alterações na subjetividade e consequentemente na sociedade e em suas instituições (Figueira, 1986). A parentalidade vem sendo construída de forma diferenciada, marcada por relações mais flexíveis e dialogadas de gênero, a função de cuidar está mais relacionada com a personalidade do indivíduo do que à sua sexualidade ou gênero (C. Santos, 2004). Ainda, é evidente a importância cada vez maior atribuída aos laços afetivos e às escolhas e, essa possibilidade de mudança adaptativa é de extrema importância na constituição do indivíduo como ser social e gregário (Rodriguez \& Paiva, 2009).

As transformações de valores ocorridas na contemporaneidade legitimam as diversas formas de se constituir família e apontam a coexistência de referências tradicionais e modernas, ou seja, ideários de família hierárquica e igualitária (Vitale, 1997). Desta forma, na contemporaneidade não há um modelo de família único, a ampliação de seu conceito e suas múltiplas possibilidades resultam na dificuldade de se abstrair um sentido único à mesma, possibilitando o aparecimento de novos arranjos familiares.

Em meio às famílias monoparentais, pluriparentais, casais sem filhos por opção, dentre outras, nos deparamos com a polêmica e recente realidade da família homoparental. A homoparentalidade vêm ganhando visibilidade e aponta um momento de experimentação e construção de novas formas de ser e de relacionar-se, perpassa questões como a vivência de papéis e funções, bem como, das influências por parte da sociedade e redes de apoio geral, como a família e a comunidade.

A construção de uma família homoparental frente o ideário da família tradicional, ainda muito vivo no imaginário social, levanta ques- tões sobre a noção de família e do que necessita uma criança na família. Pesquisas mostram que a imagem que as pessoas têm da homoparentalidade é carregada de preconceito e representações negativas (Fonseca, 2008; Grossi, 2003). Contrapondo-se a esses questionamentos e temores, pesquisadores da área (C. Santos, 2004; Tarnovski, 2002) salientam que é a capacidade de cuidar e a qualidade do vínculo com os filhos o determinante da boa parentalidade e não a orientação sexual dos pais.

Segundo o Censo de 2010 há no Brasil mais de 60 mil casais homossexuais vivendo juntos, o que aponta para a existência de um número considerável de famílias homoparentais. Essa foi a primeira edição do recenseamento do Instituto Brasileiro de Geografia e Estatística (IBGE) a contabilizar a população de casais homossexuais que residem juntos (Lauriano \& Duarte, 2011). Já com relação à adoção, a atual jurisdição brasileira é omissa quanto à possibilidade de casais homossexuais adotarem crianças ou adolescentes. O Estatuto da Criança e do Adolescente (Lei n ${ }^{\circ}$ 8.069, 1990) não se posiciona em relação à adoção por homossexuais, entretanto, tampouco aparece a referência sexual como parâmetro para adoção.

A legislação brasileira vêm flexibilizando-se e, atualmente, permite que casais homossexuais firmem união estável e o Supremo Tribunal Federal os reconhece como entidade familiar (Santos, 2011). Além disso, já foram reconhecidos processos de adoção por homossexuais assumidos no Brasil. Apesar do trâmite não ser realizado em todas as comarcas do país, a ideia começa a se espalhar e profissionais do Direito se veem na obrigatoriedade de discutir e refletir acerca da incipiente situação.

Diante dessa realidade, é de fundamental importância verificar como esses casais investem subjetivamente na possibilidade de tornarem-se pais. $\mathrm{O}$ esclarecimento acerca das representações parentais dos casais homoafetivos visa facilitar a construção da parentalidade, permitindo acesso aos fatores ainda desconhecidos que se entrelaçam com a função parental, a fim de instrumentalizar profissionais das áreas jurídica, de saúde e educacionais para que possam refletir acerca dessa nova realidade. Além de se buscar 
referências que permitam construir uma concepção de família, sem negar suas diferentes formas de expressão (Passos, 2007).

\section{A Transmissão Psíquica Familiar}

A família é o grupo relacional que se configura e vincula a partir de laços afetivos e da transmissão geracional, garantindo o equilíbrio entre o individual e o plural que todo sujeito precisa para construir sua identidade (Roudinesco, 2003). Na cadeia geracional familiar é a lei da filiação que garante um lugar simbólico para o filho na situação edípica. A transmissão psíquica familiar permite a vinculação por meio de um encadeamento de gerações, o que dá a noção de pertencimento e permite além da construção da própria subjetividade, um processo de transformação do material transmitido. É através desse processo que o sujeito se torna autor e proprietário de sua herança, permeando sua história pessoal, familiar e da própria civilização (I. C. Gomes \& Zanetti, 2009).

Kaës (1998) define dois tipos de transmissão psíquica, a transgeracional e a intergeracional. A primeira trata daquilo que é transmitido de um espaço psíquico a outro, sem a possibilidade de elaboração, já a transmissão psíquica intergeracional, difere da anterior por pressupor um trabalho de ligações e transformações entre as gerações, ou seja; quando há a possibilidade de elaboração desses conteúdos.

Sobre a transmissão psíquica transgeracional, Correa (2003) atenta ao que pode ocorrer no exercício da parentalidade, quando aquilo que não encontra inscrição no psiquismo dos pais é depositado no psiquismo da criança. A autora aponta como a criança desde sua chegada ao mundo é requerida para compartilhar os enunciados dos ancestrais, estando encarregada da continuidade geracional e da identidade familiar, o que pode custar sua integridade psíquica e somática.

\section{A Parentalidade e a Representação Parental}

O termo parentalidade surge da junção dos termos paternalidade e maternalidade e, distin- gue-se dos mesmos, por não estar relacionado ao modelo tradicional de família, retirando a ênfase do vínculo biológico e da atuação do pai e considerando o processo de construção psíquica (Solis-Ponton, 2004). A parentalidade refere-se à nomeação de vínculos de parentesco e processos psicológicos que se desenvolvem a partir destes. A principal função parental é a de garantir a construção de subjetividade ao filho, em outras palavras, um filho depende de um outro qualificado para garantir-lhe vida psíquica. Desta forma, indagar sobre as implicações da parentalidade em suas diversas formas nos parece fundamental frente a ampliação do leque de possibilidades de exercício do papel parental.

O processo de parentalização envolve questões geracionais e transgeracionais e reativa nos pais questões como o contrato narcísico. Solis-Ponton (2004) pontua que para se tornar pai/ mãe é necessário ter realizado um trabalho interior que começa pela aceitação de que herdamos algo de nossos pais. A apreensão deste modelo parental influencia a construção do vínculo dos pais com a criança e o exercício da parentalidade desses. Tornar-se pai implica agir tendo os próprios pais como modelo, sendo que não são os pais reais que ocupam o lugar das representações parentais, mas o superego parental que é transmitido de geração em geração, ou seja, as lembranças dos cuidados parentais, das regras, obrigações e interditos.

A dinâmica dos objetos internalizados relaciona-se com o modelo das relações mãe-bebê, tomado como protótipo relacional (P. B. Gomes \& Porchat, 2006). Essas representações mentais fazem parte do mundo interno do indivíduo e estão diretamente ligadas às percepções, comportamentos e atitudes. A capacidade do indivíduo se relacionar e vincular é enfatizada e, um dos mecanismos de defesa mais usados é o da projeção, no qual o indivíduo externaliza seu mundo interno projetando-o no outro, que pode constituir um representante de seus desejos e fantasias. A partir de suas relações originárias com os pais da infância, o indivíduo, em seu mundo interno, constrói uma imagem, sendo esta a representação parental. 


\section{Homoparentalidade}

Homoparentalidade é uma nomenclatura originalmente francesa, o termo foi criado em 1997 pela $\mathrm{APGL}^{2}$ (Roudinesco, 2003). É considerada uma família homoparental aquela em que ao menos um indivíduo homossexual assume a responsabilidade por uma criança. Este termo tem sido alvo de questionamentos por colocar o foco na orientação sexual dos pais ao mesmo tempo em que se refere ao cuidado dos filhos, sendo que pesquisas e estudos buscam desfazer essa associação (Eugenio, 2003). O uso deste termo no presente trabalho tem a intenção de facilitar a leitura e entendimento do leitor, além de apoiar a iniciativa de pensar e refletir sobre o novo.

O desejo de constituir família e ter filhos não é exclusivo dos casais heterossexuais e, cada vez mais, se observa casais homossexuais recorrendo à adoção ou à biotecnologia a fim de sua concretização (Fiorini, 2010). A homoparentalidade pode ser resultado de família recomposta com filhos de relacionamento heterossexual anterior, adoção ou o uso de tecnologias reprodutivas. No Brasil é mais comum encontrar famílias homoparentais com filhos que são fruto de relacionamentos heterossexuais anteriores. $\mathrm{O}$ tema da adoção por homossexuais, todavia permanece em pauta e, portanto, este direito não está garantido aos homossexuais, dificultando o acesso ao mesmo (Farias \& Maia, 2009).

São dois os argumentos que vêm sendo utilizados contra a homoparentalidade: a necessidade de preservação da instituição família, contra o casamento e a filiação homossexual e; a necessidade de resguardar o simbólico como condição da cultura e emergência da subjetividade. Observa-se no contexto particular a resistência ao reconhecimento de outras formas de família e parentesco e, para sustentar tais argumentos, utilizam-se referências psicanalíticas diversas, como a do dispositivo sexual (Arán, 2010). Além disso, questiona-se acerca da saúde mental dos homossexuais, da compatibilidade de homos-

2 Associação de Pais e Futuros Pais Gays e Lésbicas. sexualidade e parentalidade e da tendência dos filhos se tornarem homossexuais (Uziel, 2002).

Dentre as preocupações que permeiam a homoparentalidade encontram-se ainda questões como a identificação primária da criança, o complexo de Édipo e a cena primária (Smola, 2010). Considerando uma das premissas básicas da psicanálise clássica, de que a presença da diferença sexual no casal parental é fundamental na estruturação psíquica humana, um dos fatores de maior questionamento a respeito do casal homoparental é se o mesmo poderá oferecer à criança a imagem diversificada da diferença sexual anatômica necessária para o desenvolvimento do psiquismo infantil (Carrasco, 2010; Fiorini, 2010).

Agacinski (1998), citado por Butler (2003), afirma que o parentesco homossexual é uma prática que se afasta da natureza e da cultura, além de retratar um tipo de violência ou destruição ao abolir a dupla origem de uma criança, vista por ela como o alicerce cultural e simbólico. Enquanto isso, pesquisas apresentam saídas criativas para o exercício da parentalidade de casais homoafetivos masculinos, como o estudo de Zambrano (2006) que aponta o reconhecimento da necessidade de uma pessoa do sexo feminino para ajudar nos cuidados com a criança, concluindo que o contato com os dois sexos não precisa ocorrer só dentro da célula familiar (Fiorini, 2010).

Contrapondo-se à visão determinista dos autores que afirmam ser a diferença sexual fundamental na triangulação da criança dentro de uma família, teóricos esclarecem que o pai e a mãe não precisam existir realmente, mas podem ser posições ou figuras imaginárias (Butler, 2003), ou seja, a presença das figuras deve ocorrer estruturalmente de alguma maneira. Perelson (2005) se utiliza dos termos posição materna e posição paterna para desvincular o sexo biológico dos pais de suas atuações no seio da família. Féres-Carneiro (2009) aponta que na família homoparental essas funções não tem uma determinação biológica, mas sim, subjetiva e dessa maneira cada sujeito constitui um lugar junto à criança, marcando sua presença e exercendo uma função. 
Assim, apesar do grande valor dado aos aspectos biológicos em nossa cultura, sendo estes considerados os formadores dos vínculos familiares mais verdadeiros, o crescente aparecimento de diversas configurações familiares mostra que parentesco e filiação são construções sociais (Tarnovski, 2002). A contemporaneidade vem apresentando a parentalidade sendo exercida cada vez mais por várias pessoas; vários pais e mães, além da ênfase na vida em família, no lugar e papel desempenhado por cada um, o que tende a preservar o equilíbrio da dinâmica familiar (Garbar \& Theodore, 2000). Passos (2005) aponta que essa nova composição familiar tende a ser marcada pela ausência de papéis fixos entre os membros, pela inexistência de hierarquias e maior circulação das lideranças no grupo, pela presença de múltiplas formas de composição familiar e, consequentemente, de formação dos laços afetivos e sociais, o que possibilita distintas referências de autoridade, tanto dentro do grupo como no mundo externo.

Rodriguez e Paiva (2009) apontam o preconceito como um fator chave na dificuldade do exercício da homoparentalidade, assinalando uma ruptura dos filhos com a própria história, suas famílias de origem. A falta de aceitação das famílias de origem dos casais e da sociedade corrobora na manutenção do conflito do casal homoafetivo na conciliação da vivência da conjugalidade homoafetiva e da parentalidade. A necessidade de uma rede de apoio faz com que muitos homossexuais tenham como família eleita um grupo de amigos íntimos. Neste novo grupo, eles se deparam com a possibilidade de vivenciar papéis mais flexíveis dentro de uma família e uma maior liberdade para experimentar e se adequar as suas necessidades (Nunan, 2007).

Moris (2008) ressalta que são práticas cotidianas e disseminadas em esferas sociais diversas a perseguição e marginalização dos homossexuais, presente de forma subliminar ou direta nas relações profissionais, religiosas, comerciais e familiares. No contexto brasileiro, esses pais serão o grupo minoritário excluído e terão de lidar tanto com o peso de serem diferentes quanto com o preconceito associado à condição de pais homossexuais, com enfrentamentos típicos como a cobrança e o olhar desconfiado da sociedade concernente ao exercício da parentalidade.

Apesar do desconhecimento, do preconceito e de todos os dificultadores dessa nova realidade que é a homoparentalidade, a construção de uma família continua a ser almejada por estes sujeitos (Roudinesco, 2003). O esforço dos homossexuais em construir família está relacionado ao desejo de pertencimento, de fazer parte de uma prática socialmente aceita e valorizada. Esse anseio de constituir família deve-se ao benefício que Bourdieu (1996) chama de lucro simbólico da normalidade, que seria a pressão social para se adequar a norma da família, representação instituída como a-histórica, universal e natural, entretanto, as noções de normalidade e estabilidade sugerem uma ideia de um modelo familiar pré-existente e invariável. Além do desejo de constituir família para ser socialmente aceito, há também o desejo de transmissão de um patrimônio cultural e psíquico, desta forma, a parentalidade para os homossexuais seria também uma maneira de oferecer um filho aos próprios pais decepcionados ao se verem privados de descendência (Eiguer, 2010).

\section{A Pesquisa}

A pesquisa que embasa este trabalho investigou a representação parental de casais homossexuais masculinos, por meio das imagos parentais e legados geracionais, atualizados pelo processo de transmissão psíquica. O estudo buscou construir conhecimento acerca das novas formas de se relacionar e vivenciar a parentalidade, em função do crescente aparecimento de novos arranjos familiares. O método escolhido foi o clínico-qualitativo (Turato, 2003), que tem como principal instrumento de coleta e registro dos dados em campo o próprio pesquisador, suas percepções e sua consciência diante dos fenômenos.

Os instrumentos utilizados foram a entrevista semi-dirigida e os Desenhos de Família com Estórias, uma variação do Procedimento de Desenho-estória, criado por Trinca (1997), do qual foi requerido apenas um desenho: a família 
que gostaria de ter. A entrevista semi-dirigida é usada quando o pesquisador busca informações mais específicas e, portanto, introduz um tema e guia a discussão para questões concernentes ao tema pesquisado (Turato, 2003), permitindo que a direção da entrevista seja dada alternadamente e que elementos relevantes possam ser explorados no decorrer da mesma. $\mathrm{O}$ instrumento de Desenhos de Família com Estórias (DF-E) tem por finalidade a investigação de aspectos intrapsíquicos e intrafamiliares da pessoa no contexto da família. Através do DF-E é possível detectar angústias inconscientes que estão presentes nas relações de objeto da pessoa, além de representações relacionais e imagos relacionadas à família.

A amostra foi constituída por cinco casais homossexuais masculinos que viviam em união estável por um período mínimo de dois anos, o que é considerado pela jurisprudência brasileira como união estável legal para casais heterossexuais e, sem filhos. A escolha por casais sem filhos deveu-se à tentativa de desvincular a representação parental da experiência real. Não houve restrição de idade ou relação com o desejo e/ou plano de ter filhos no futuro. Os primeiros colaboradores foram contatados através de amigos e conhecidos da pesquisadora e da Associação Casarão Brasil. O restante da amostra foi construído através da técnica de amostragem chamada bola de neve (Mattar, 2001), na qual os participantes seguintes da amostra são recrutados a partir da rede de conhecidos daqueles já presentes na amostra, formando assim cadeias de referência.

Os encontros aconteceram na casa dos colaboradores e tiveram a duração média de três horas. As entrevistas foram realizadas com os casais e abordou temas a respeito da história do casal, relacionamento conjugal, família de origem, bem como, a família ideal e o desejo por filhos. Após o término da entrevista foi aplicado o procedimento de DF-E, cada um dos parceiros produziu um desenho e a aplicação ocorreu em conjunto, em seguida a pesquisadora pediu para cada participante contar uma estória associada ao seu desenho.

A análise dos dados da entrevista foi feita com base no referencial psicanalítico vincular, levando em conta preceitos psicanalíticos bási- cos, como: a valorização da transferência e da contratransferência. Os DF-E foram analisados e interpretados seguindo o referencial do autor do procedimento (Trinca, 1997) levando em conta os conteúdos inconscientes que apareceram nos desenhos e nas estórias dos desenhos. A análise associou os dados obtidos através dos dois instrumentos (entrevista e DF-E adaptado) por meio de cinco grandes categorias, para cada casal em separado. A escolha das categorias está diretamente ligada ao conteúdo do material coletado e seus temas marcantes e recorrentes. São elas:

1. Observações da pesquisadora e aspectos transferenciais e contratransferenciais,

2. Família de Origem e Identidade Homossexual,

3. Desenhos, Idealizações e Imaginários Familiares,

4. Conjugalidade,

5. Representação Parental.

\section{Os Resultados}

Os achados mais significativos da referida pesquisa nos levam de volta ao ponto nodal que é a família de origem, no quesito da aceitação da homossexualidade dos filhos e sua influência direta na elaboração psíquica de uma identidade homossexual. A análise do material coletado permitiu a percepção de uma forte ligação dos casais com as famílias de origem, cuja falta de aceitação destas, acerca da orientação sexual, pode impedir a construção de uma identidade íntegra. A forte influência das famílias de origem em suas subjetividades aparece como a primeira luta a ser superada a fim de que eles possam se constituir como sujeitos de desejo e, então poder pensar na parentalidade. A dificuldade de separar-se das famílias de origem associada ao conflito da aceitação apareceu como um empecilho na elaboração identitária em todos os casos.

Outra peculiaridade pôde ser notada nos casais homoafetivos. A concepção de união estável criada com base no modelo heteronormativo tem outro valor, pois tendem a mergulhar em relacionamentos compromissados (namoro e coabitação) em curto espaço de tempo, o que parece estar ligado ao desejo de encontrar apoio em 
outro igual, já que usualmente isto não provem de suas famílias. A repetição dos modelos heteronormativos apareceu com frequência na observação da conjugalidade dos casais entrevistados. $\mathrm{O}$ apego ao modelo heterossexual (o conhecido deles), de seus pais, parentes e sociedade em geral, pôde ser percebido através de falas sobre divisão de tarefas e na posição de complementaridade existente na dinâmica relacional do casal. A construção de um novo modelo conjugal para os casais da pesquisa está ligada aos referenciais de gênero, por exemplo: com a distinção das atividades da casa como femininas/masculinas. Eles buscam (declaram em seu discurso) sua singularidade, tentando exercitar maior flexibilidade de poder, entretanto parecem retornar ao velho modelo heteronormativo.

Estes dados condizem com resultados apresentados em outras pesquisas, como de Manzi-Oliveira (2009) e Rodriguez e Paiva (2009) que apontam que os casais homoafetivos seguem o modelo heteronormativo, apresentando discursos recorrentes de comparação com casais heterossexuais. Os casais da pesquisa remetem aos referenciais disponíveis na sociedade do que é a parentalidade: os pais que tiveram, os casais heterossexuais que conhecem e até mesmo o modelo tradicional de pai. Os questionamentos feitos por eles são o reflexo da vida em uma sociedade na qual a homofobia e o heterossexismo fazem parte do senso comum, da vida cotidiana e dos valores compartilhados.

O preconceito com o qual os homossexuais têm que aprender a lidar, nos diferentes âmbitos de suas vidas, parece ganhar força quando a família de origem rechaça o filho. A surpresa das famílias diante da descoberta ou notícia da homossexualidade dos filhos vem carregada de preconceito, resultando com frequência no rompimento dos laços, sendo mais comum com a figura paterna. Os indivíduos que se assumem como homossexuais estão sujeitos a um longo e complexo processo de elaboração identitária, buscando maneiras de compensar e superar o preconceito e falta de apoio. O processo de reconstrução dessas relações e laços familiares, relatado pelos participantes, deixa marcas e permeia a vivência da conjugalidade homoafetiva.
Apesar do intuito primevo da pesquisa ter sido acessar a representação parental desses casais, o tema da assunção da homossexualidade dentro da família de origem foi o que perdurou, dominando o discurso dos colaboradores durante os encontros. A maior parte dos entrevistados partiu da questão específica da assunção, pontuando as dificuldades vividas, como o sofrimento em não ser aceito e o preconceito experimentado dentro e fora de casa. A elaboração do conflito identitário, vivenciado pelos homossexuais, tem um peso razoável e ocupa um espaço considerável na psique desses participantes.

A parentalidade auxilia o indivíduo na luta contra a pulsão de morte e propicia um sentimento de continuidade existencial, entretanto poder planejá-la envolve a resolução interna de deixar o lugar de filho para ocupar o de pai/mãe. O discurso dos casais não aponta o desejo concreto de parentalidade, seus imaginários parentais parecem estar alicerçados na vivência que eles tiveram em suas casas, com os seus próprios pais e as dívidas não resolvidas os impedem de deixar seus lugares de filho e assumir a responsabilidade por um filho. Fica claro que também para os casais homoafetivos ainda é difícil assumir essa nova forma familiar que vem carregada de dúvidas: a homoparentalidade.

As motivações conscientes e inconscientes do não-desejo parecem ter surgido num emaranhado confuso de modelos, de discursos e possibilidades de ser, refletindo um tipo de constituição psíquica nas quais suas subjetividades não encontram eco no mundo para poder elaborar seus conflitos internos. Como pontua Levinzon (2006), o desejo de ter filhos surge como parte da evolução normal do processo edipiano, no qual há a identificação do filho com o genitor do mesmo sexo, por meio da possibilidade do exercício do papel semelhante ao dele. Diante de uma acentuada identificação com a mãe, do conflito relacionado ao desabrochar da homossexualidade do filho dentro da família, da figura de um pai que com frequência aparece desobjetalizado, a possibilidade de fazer a escolha consciente de exercer a parentalidade aparece então repleta de entraves psíquicos, somado a censura ou veto consciente familiar e social. 
Acerca dos participantes que relataram desejar se tornar pai um dia, o discurso manifesto refere com veemência uma parentalidade reparatória, ou seja: o desejo de suprir as faltas que sentiram como filhos através da possível vivência parental futura. Indo de encontro ao que os autores Futino e Martins (2006) apontam em seu artigo acerca dos pais homossexuais apresentarem como expectativas em relação ao futuro: o desejo de felicidade e aprendizado da tolerância frente até à heterossexualidade do filho.

\section{Considerações Finais}

Os casais entrevistados vivem a construção de uma conjugalidade concomitante ao processo de aceitação e elaboração identitária homossexual. A falta de apoio, o estremecimento dos laços familiares diante da homossexualidade parece ter sido o elemento fundamental na constituição de um sentimento turvo e complexo com relação à possibilidade do exercício da parentalidade.

Esses possíveis futuros pais estão implicados à referência de seus próprios pais. $\mathrm{O}$ acesso à parentalidade supõe além da perda da posição de filho, a reativação da identificação destes com suas figuras parentais. A permuta simbólica de lugares, como organizadora da transmissão/sucessão geracional não é entrave para os casais homossexuais, mas ocorre de forma similar (Ducousso-Lacaze \& Grihom, 2010). A orientação sexual não é um obstáculo ao trabalho psíquico indispensável para a renúncia da posição de filho, entretanto, há um fator singular: esse processo de permuta ocorre de forma muito distinta, pois se por um lado o indivíduo precisa ser re-aceito como filho para poder pensar em deixar esse lugar de filho, com a chegada dos netos os pais muitas vezes flexibilizam-se e aceitam (mesmo que com reservas e de forma prematura para seus psiquismos) a família homoparental.

As famílias homoparentais carregam dúvidas e incertezas quando comparadas à primazia do modelo heterossexual, vigente até hoje. A homoparentalidade vem questionar o modelo de complementaridade bipolar entre o feminino e masculino e, o complexo de Édipo como es- truturantes da identidade e subjetividade. Essa família só poderá adquirir outro status, mais próximo da normalidade, se aceitarmos outra lógica como instituinte do ser humano, uma lógica pautada na supremacia dos vínculos e funções, independente do sexo biológico (Rodriguez \& Gomes, 2012). A proposta de ênfase no vínculo filiativo como base na construção de um novo modelo relacional, conjugal, familiar e parental pretende facilitar a compreensão dos processos de subjetivação que decorrem das distintas maneiras em se constituir vínculos.

\section{Conclusão}

Conclui-se com esta pesquisa que a falta de elaboração da questão homossexual (identitária e familiar/social) impede que casais homoafetivos masculinos cheguem à parentalidade, pois eles estão presos à suas famílias de origem, com questões e conflitos a resolver. Isso não quer dizer que no futuro estes mesmos colaboradores não tenham chances de desejar se tornar pais e até tornarem-se, mas que no dado momento seus psiquismos se ocupam com outras prioridades, como o complexo processo de construção de uma identidade e de uma relação conjugal não normatizadas pelo sexo biológico e, por fazer parte de uma sociedade usufruindo de sua legislação.

É desafiador para a psicanálise pensar a realidade das experiências homoparentais, do ponto de vista teórico e prático. Qualquer que seja a idade, o sexo, a orientação sexual ou condição social, todos desejam uma família, o pertencimento (Roudinesco, 2003) e, a construção dessa nova família, a homoparental, em todo seu cenário, ocorre de maneira lenta e gradual, repleta de expectativas e cautelas (Manzi-Oliveira, 2009). O decretado desejo pela adoção por parte de alguns participantes aponta a tentativa de formar uma família, sob o modelo tradicional de família na qual sem filhos não se constitui família. O caminho que irão trilhar para a parentalidade deve ser visitado pela psicanálise a fim de fornecermos ferramentas para pensar, refletir e compreender as vicissitudes da família nos dias de hoje. 
Diante da necessidade de libertação da égide do biológico presente no ideário da família tradicional, é preciso reconhecer o vínculo como fator chave nas relações familiares, permitindo à família funcionar como dispositivo de continência psíquica, além de envolver a criação de laços inconscientes e transmissão psíquica (Benghozi, 2010).

O tema da homoparentalidade causa ainda muitos questionamentos e reservas, diante disso nos cabe estudar e pesquisar a fim de fornecer respaldo teórico a essas novas formas de constituir família e parentalidade. Espera-se que os estudos seguintes possam dar continuidade ao estabelecimento de uma relação produtiva entre a psicanálise e as novas formas de construção de gênero e parentalidade na cultura contemporânea (Arán, 2009), em que as alteridades ultrapassem os limites do simbólico e da própria teoria psicanalítica, sendo cada indivíduo aceito em sua singularidade, para além das definições prescritas da heteronormatividade, em consonância com o contínuo processo de reinvenção dos modos de ser e de se relacionar.

\section{Referências}

Amazonas, M. C. L. A., \& Braga, M. G. R. (2006). Reflexões acerca das novas formas de parentalidade e suas possíveis vicissitudes culturais e subjetivas. Ágora (Rio de Janeiro), 9(2), 177 191. doi:10.1590/S1516-14982006000200002

Arán, M. (2009, dez.). A psicanálise e o dispositivo diferença sexual. Revista Estudos Feministas (Florianópolis), 17(3), 653-673. doi:10.1590/ S0104-026X2009000300002

Arán, M. (2010). Políticas do desejo na atualidade: A psicanálise e a homoparentalidade. In M. R. Prata (Ed.), Sexualidades (pp. 47-60). Rio de Janeiro, RJ: Contracapa.

Benghozi, P. (2010). Malhagem, filiação e afiliação. Psicanálise dos vínculos: Casal, família, grupo, instituição e campo social (E. D. Galery, Trad.). São Paulo, SP: Vetor.

Borges, C. C., \& Coutinho, M. L. R. (2008). Família e relações intergeracionais no Brasil hoje: Novas configurações, crises, conflitos e ambigüidades. In I. C. Gomes (Ed.), Família: Diagnóstico e abordagens terapêuticas (pp. 45-59). Rio de Janeiro, RJ: Guanabara Koogan.
Bourdieu, P. (1996). O espírito da família. In P. Bourdieu, Razões práticas (pp. 124-135). Campinas, SP: Papirus.

Butler, J. (2003). O parentesco é sempre tido como heterossexual? Cadernos Pagu, 21, 219-260. doi:10.1590/S0104-83332003000200010

Carrasco, A. M. (2010). Adoção homoparental. In E. Rotenberg \& B. A. Wainer (Eds.), Homoparentalidades: nuevas familias (2. ed., pp. 71-76) Buenos Aires, Argentina: Lugar.

Correa, O. B. R. (2003). Transmissão psíquica entre as gerações. Psicologia USP, 14(3), 35-45.

Ducousso-Lacaze, A., \& Grihom, M. (2010). Homoparentalité apports d'une approche psychanalytique. Revue de Thérapie Familiale Psychanalitique, 2(25). doi:10.3917/difa.025.0125

Eiguer, A. (2010). Homoparentalidades, afiliación y vínculo filial. In E. Rotenberg \& B. A. Wainer (Eds.), Homoparentalidades: nuevas famílias (2. ed., pp. 127-138). Buenos Aires, Argentina: Lugar.

Eugenio, F. (2003). De pais, mães e filhos: Discursos e reinvindicações da homoparentalidade (Tese de doutorado em Antropologia, Universidade Federal do Rio de Janeiro, RJ, Brasil).

Farias, M. O., \& Maia, A. C. B. (2009). Adoção por homossexuais: A família homoparental sob o olhar da psicologia jurídica. Curitiba, PR: Juruá.

Féres-Carneiro, T. (2009). Casal e família: Permanências e rupturas. Rio de Janeiro, RJ: Casa do Psicólogo.

Figueira, S. A. (1986). Uma nova família? O moderno e o arcaico na família de classe média brasileira. Rio de Janeiro, RJ: Jorge Zahar.

Fiorini, L. G. (2010). Reflexiones sobre la homoparentalidad: parentalidad em parejas homossexuales. In E. Rotenberg \& B. A. Wainer (Eds.), Homoparentalidades: nuevas familias (2. ed., pp. 47-56). Buenos Aires, Argentina: Lugar.

Fonseca, C. (2008). Homoparentalidade: Novas luzes sobre o parentesco. Revista Estudos Feministas (Florianópolis), 16(3), 769-783. doi:10.1590/ S0104-026X2008000300003

Futino, R. S., \& Martins, S. (2006). Adoção por homossexuais: Uma nova configuração familiar sob os olhares da psicologia e do direito. Revista Aletheia, 24, 149-159. 
Garbar, C., \& Theodore, F. (2000). Família mosaico. São Paulo, SP: Augustus.

Giddens, A. (1993). A transformação da intimidade (2. ed.) São Paulo, SP: Editora da Universidade Estadual Paulista Júlio de Mesquita Filho.

Gomes, I. C., \& Zanetti, S. (2009). Transmissão psíquica transgeracional e construção de subjetividade: Relato de uma psicoterapia psicanalítica vincular. Psicologia USP, 20(1), 93-108. doi:10.1590/S0103-65642009000100006

Gomes, P. B., \& Porchat, I. (2006). Psicoterapia do casal. São Paulo, SP: Casa do Psicólogo.

Grossi, M. P. (2003). Gênero e parentesco: Famílias gays e lésbicas no Brasil. Cadernos Pagu, 21, 261-280. doi:10.1590/S010483332003000200011

Kaës, R. (1998). Os dispositivos psicanalíticos e as incidências da geração. In A. Eiguer, A transmissão do psiquismo entre gerações: Enfoque em terapia familiar psicanalítica (pp. 5-19). São Paulo, SP: Unimarco.

Lauriano, C., \& Duarte, N. (2011, 29 abr.). Censo 2010 contabiliza mais de 60 mil casais homossexuais. G1. Recuperado em http://g1.globo.com/ brasil/noticia/2011/04/censo-2010-contabiliza-mais-de-60-mil-casais-homossexuais.html

Lei $\mathrm{n}^{\circ}$ 8.069, de 13 de julho de 1990. (1990). Estatuto da criança e do adolescente. Brasília, DF: Centro Gráfico do Senado Federal.

Levinzon, G. K. (2006). A adoção na clínica psicanalítica: O trabalho com os pais adotivos. Mudanças - Psicologia da Saúde, 14(1), 24-31.

Manzi-Oliveira, A. B. (2009). Adoção por casais homoafetivos: Relato de seus protagonistas [Monografia]. Ribeirão Preto, SP: Universidade de São Paulo.

Mattar, F. N. (2001). Pesquisa de marketing. São Paulo, SP: Atlas.

Moris, V. L. (2008). Preciso te contar? - Paternidade homoafetiva e a revelação para os filhos (Tese de doutorado, Pontifícia Universidade Católica de São Paulo, SP, Brasil).

Moscheta, M. S., \& Santos, M. A. (2009). Relação conjugal homoafetiva: Revolução ou acomodação? In M. V. Cunha, S. R. Pasian, \& G. Romanelli (Eds.), Pesquisas em Psicologia: Múltiplas abordagens (pp. 129-152). São Paulo, SP: Vetor.
Nunan, A. (2007). Influência do preconceito internalizado na conjugalidade homossexual masculina. In M. P. Grossi, A. P. Uziel, \& L. Mello (Eds.), Conjugalidades, parentalidades e identidades lésbicas, gays e travestis (pp. 47-67). Rio de Janeiro, RJ: Garamond.

Passos, M. C. (2005). Homoparentalidade: Uma entre outras formas de ser família. Psicologia Clínica, 17(2), 31-40. doi:10.1590/S010356652005000200003

Passos, M. C. (2007, nov.). A constituição dos laços na família em tempos de individualismo. Mental (Barbacena), 5(9).

Perelson, S. (2005). A parentalidade homossexual: Uma exposição do debate psicanalítico no cenário francês atual. Revista Estudos Feministas (Florianópolis), 14(3), 709-730. doi:10.1590/ S0104-026X2006000300008

Rodriguez, B. C., \& Gomes, I. C. (2012). Novas formas de parentalidade: Do modelo tradicional à homoparentalidade. Boletim de Psicologia, 62(136), 29-36.

Rodriguez, B. C., \& Paiva, M. L. S. C. (2009, jun.). Um estudo sobre o exercício da parentalidade em contexto homoparental. Revista Vínculo, 6(1), 13-25.

Roudinesco, E. (2003). A família em desordem. Rio de Janeiro, RJ: Jorge Zahar.

Santos, C. (2004). A parentalidade em familias homossexuais com filhos: Um estudo fenomenológico de vivências de gays e lésbicas (Tese de doutorado, Faculdade de Filosofia, Ciências e Letras, Universidade de São Paulo, Ribeirão Preto, SP, Brasil).

Santos, D. (2011, 05 maio). Supremo reconhece união estável de homossexuais. G1. Recuperado em http://g1.globo.com/brasil/noticia/2011/05/ supremo-reconhece-uniao-estavel-de-homossexuais.html

Smola, A. (2010) Homoparentalidades. In E. Rotenberg \& B. A. Wainer (Eds.), Homoparentalidades: nuevas familias (2. ed., pp. 63-70). Buenos Aires, Argentina: Lugar.

Solis-Ponton, L. (Ed.). (2004). Ser pai, ser mãe: Parentalidade. Um desafio para o terceiro milênio (M. C. P. Silva, Rev. Técn. Trad.). São Paulo, SP: Casa do Psicólogo.

Tarnovski, F. L. (2002). Pais assumidos: Adoção e paternidade homossexual no Brasil contempo- 
râneo (Dissertação de mestrado em Antropologia Social, Universidade Federal de Santa Catarina, Florianópolis, SC, Brasil).

Trinca, W. (1997). Formas de investigação clinica em psicologia: Procedimento de desenhos com estórias. São Paulo, SP: Vetor.

Turato, E. R. (2003). Tratado da metodologia da pesquisa clínico-qualitativa: Construção teórico-metodológica, discussão comparada e aplicação nas áreas de saúde e humanas. Petrópolis, RJ: Vozes.

Uziel, A. P. (2002). Família e homossexualidade: Velhas questões, novos problemas (Tese de doutorado em Ciências Sociais, Universidade Estadual de Campinas, SP, Brasil).
Vitale, M. A. F. (1997). Socialização e família: Uma análise intergeracional. In M. C. B. Carvalho, $A$ família contemporânea em debate (2. ed., pp. 89-96) São Paulo, SP: Cortez.

Zambrano, E. (2006). Parentalidades “impensáveis": Pais/mães homossexuais, travestis e transexuais. Horizontes Antropológicos, 12(26), 123-147. doi:10.1590/S0104-71832006000200006

Recebido: $28 / 05 / 2012$

$1^{a}$ revisão: $29 / 10 / 2014$ Aceite final: 10/03/2015 